\title{
The principle of minimum entropy production and snow structure
}

\author{
Perry BARTELT, Othmar BUSER \\ WSL Swiss Federal Institute for Snow and Avalanche Research SLF, Flüelastrasse 11, CH-7260 Davos Dorf, Switzerland \\ E-mail: bartelt@slf.ch
}

\begin{abstract}
An essential problem in snow science is to predict the changing form of ice grains within a snow layer. Present theories are based on the idea that form changes are driven by mass diffusion induced by temperature gradients within the snow cover. This leads to the well-established theory of isothermal- and temperature-gradient metamorphism. Although diffusion theory treats mass transfer, it does not treat the influence of this mass transfer on the form - the curvature radius of the grains and bonds - directly. Empirical relations, based on observations, are additionally required to predict flat or rounded surfaces. In the following, we postulate that metamorphism, the change of ice surface curvature and size, is a process of thermodynamic optimization in which entropy production is minimized. That is, there exists an optimal surface curvature of the ice grains for a given thermodynamic state at which entropy production is stationary. This state is defined by differences in ice and air temperature and vapor pressure across the interfacial boundary layer. The optimal form corresponds to the state of least wasted work, the state of minimum entropy production. We show that temperature gradients produce a thermal non-equilibrium between the ice and air such that, depending on the temperature, flat surfaces are required to mimimize entropy production. When the temperatures of the ice and air are equal, larger curvature radii are found at low temperatures than at high temperatures. Thus, what is known as isothermal metamorphism corresponds to minimum entropy production at equilibrium temperatures, and so-called temperature-gradient metamorphism corresponds to minimum entropy production at nonequilibrium temperatures. The theory is in good agreement with general observations of crystal form development in dry seasonal alpine snow.
\end{abstract}

\section{INTRODUGTION}

Mass transport, heat transfer and phase changes are the fundamental thermodynamic processes in the snow cover. Animportant phenomenon, metamorphism - the change of ice grain forms of the snow cover over time - is induced by these processes. Traditionally, metamorphism has been studied using the concepts of mass and energy conservation which require a detailed knowledge of the movement of water molecules on the ice surface or the diffusion of water vapor in the pore space. For an overview, see Colbeck (1987). Rate equations describing grain growth have been proposed (Colbeck, 1983; Gubler, 1985; Lehning and others, 2002) with the goal of modeling the development of the seasonal snow cover (Brun and others, 1992; Bartelt and Lehning, 2002).

The application of heat and mass transport principles is essential for understanding the processes involved in snow metamorphism; however, conservation principles do not include geometric aspects and cannot solve the problem of form. This is evident in the present generation of metamorphism models which predict growth rates and crystal size, but the form changes are still based on empirical parameterizations of field or laboratory observations (Brun and others, 1992; Lehning and others, 2002). Metamorphism can be described by such relationships, but not the underlying principle.

The question is whether there exists a simple thermodynamic function related directly to form. Such a function would provide a thermodynamic principle that would allow the determination of the natural snow structure under welldefined thermodynamic constraints such as the temperature state, the applied temperature gradient and mass supply. Heat-transfer engineers use such functions because they try to reduce the increase in entropy per unit time, the so-called entropy production (Bejan, 1996). During the design of a thermodynamic system (e.g. a heat exchanger), their objective is to find an optimal geometric arrangement of system components such that entropy production is minimized. The minimum of entropy production corresponds to a thermodynamic state where the least work is dissipated (Prigogine, 1980, p. 88). In geophysics and biology the principle of minimum entropy production has been applied to see if the minimum entropy production yields the optimal or natural visible form of river basins or living trees (Bejan, 2000). Natural scientists argue that the optimal form arises out of the competition between at least two mechanisms, or two driving forces, and their respective fluxes. A similar principle was used by Bejan (2000) to predict the formation of snowflakes. Since the conjugate forces and fluxes are also the source of increasing entropy, the final form is the one that makes entropy production stationary. In a thermodynamic system, the driving forces can be temperature and pressure, and the corresponding fluxes are heat and mass flows.

In snow the mass fluxes are the reason for the changes in form of the ice grains. The driving force is the difference in water-vapor pressure over the ice surface which depends on 


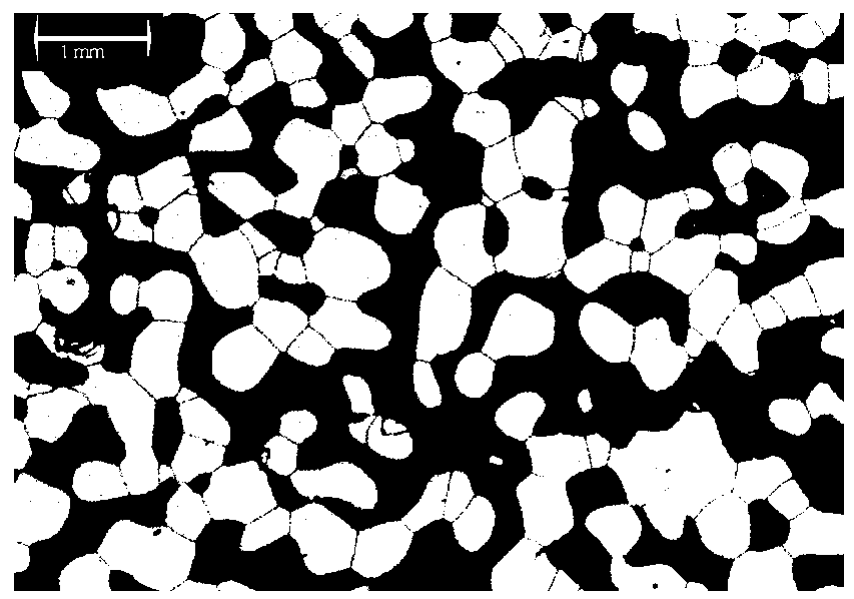

Fig. 1. A detail of snow showing the grain bonding and crystal boundaries (SLF). Note the existence of both positive and negative curvatures.

temperature and the curvature radius of the ice grains. This force and flux produce entropy, together with other formdependent and form-independent processes. In the following, we postulate that the form of the ice grains will be changed until the entropy production is a minimum within the constraints given by the thermodynamic variables $(p, T$, $V)$. This will be a non-equilibrium steady state. In view of this, we must:

Identify the irreversible (entropy-producing) processes within a clearly defined thermodynamic control volume.

Express the irreversible processes in terms of the geometric arrangement of ice grains.

Find the optimal "form" for stationary entropy production by minimizing the entropy production function with respect to a "form" variable.

The irreversible processes are formulated using constitutive relations for heat conductivity and mass transfer. It is important to note that not all thermodynamic processes produce entropy. For instance, sublimation and subsequent deposition do not produce entropy because phase changes are reversible and thus isentropic processes. The model for the geometric arrangement of the ice grains will be a commonly used model for snow microstructure applications (Lehning and others, 2002; Miller, 2002): the grains are uniform spheres of polycrystalline ice that are bonded together by necks (Fig. 1). Such forms are found typically in dry, early-winter seasonal alpine snowpacks. The single ice crystals are joined together at crystal boundaries; the grains are joined together at the necks. A grain can consist of many single crystals. The crystal boundaries can be seen as fine dark lines in Figure 1. Under sufficient magnification, they appear as grooves. The migration of molecules along these grooves is not the subject of our investigations. Hence, for a given density, our model contains two independent form parameters, the sphere's curvature radius and the radius of the neck. We will choose the curvature radius of the grain surface as the appropriate form variable. We can easily find the minimum entropy production by differentiating the sum of the entropy-producing terms with respect to curvature radius.

In summary, we hypothesize that metamorphism develops toward a non-equilibrium steady state where the entropy production is a minimum and therefore stationary.
Table 1. Nomenclature of thermodynamic variables. The subscripts are: $\mathrm{i}=$ ice, $\mathrm{a}=$ air, $\mathrm{v}=$ vapor, $\mathrm{g}=$ grain, $\mathrm{n}=$ neck, $\mathrm{b}=$ boundary (interfacial) layer, $\mathrm{s}=$ saturation. The double prime superscript denotes a quantity per unit area

\begin{tabular}{|c|c|c|}
\hline$A_{\mathrm{s}}$ & Specific surface area of the ice--air interface & $\mathrm{m}^{2} \mathrm{~m}^{-3}$ \\
\hline$h$ & Interfacial heat-transfer coefficient & $\mathrm{W} \mathrm{m}^{-2} \mathrm{~K}^{-1}$ \\
\hline$h_{\mathrm{m}}$ & $\begin{array}{l}\text { Interfacial mass-transfer coefficient with } \\
\text { respect to density difference }\end{array}$ & $\mathrm{m} \mathrm{s}^{-1}$ \\
\hline$\tilde{h}_{\mathrm{m}}$ & $\begin{array}{l}\text { Interfacial mass-transfer coefficient with } \\
\text { respect to pressure difference }\end{array}$ & $\mathrm{s} \mathrm{m}^{-1}$ \\
\hline$k_{\mathrm{i}}, k_{\mathrm{a}}$ & Thermal conductivities, ice and air & $\mathrm{W} \mathrm{m}^{-1} \mathrm{~K}^{-1}$ \\
\hline & Mass flow rate in pore space & $\mathrm{kg} \mathrm{s}^{-1}$ \\
\hline$\dot{m}_{\mathrm{i} \leftrightarrow \mathrm{v}}^{\prime \prime}$ & $\begin{array}{l}\text { Mass flux across interfacial layer per } \\
\text { surface area }\end{array}$ & $\mathrm{kg} \mathrm{s}^{-1} \mathrm{~m}^{-2}$ \\
\hline$\dot{m}_{\mathrm{g} \leftrightarrow \mathrm{v}}^{\prime \prime}$ & $\begin{array}{l}\text { Mass flux across interfacial layer per grain } \\
\text { surface area }\end{array}$ & $\mathrm{kg} \mathrm{s}^{-1} \mathrm{~m}^{-2}$ \\
\hline$\dot{m}_{\mathrm{n} \leftrightarrow \mathrm{v}}^{\prime \prime}$ & $\begin{array}{l}\text { Mass flux across interfacial layer per neck } \\
\text { surface area }\end{array}$ & $\mathrm{kg} \mathrm{s}^{-1} \mathrm{~m}^{-2}$ \\
\hline$\mu$ & Viscosity of air $\left(\mu=2.0 \times 10^{-6} \mathrm{~Pa} \mathrm{~s}\right)$ & $\mathrm{Pa} s$ \\
\hline$M_{\mathrm{v}}$ & Molecular mass of water vapor & $\mathrm{kg} \mathrm{mol}^{-1}$ \\
\hline$p_{\mathrm{a}}, p_{\mathrm{v}}$ & Partial pressures, air and water vapor & $\mathrm{Pa}$ \\
\hline $\bar{p}_{\mathrm{s}}$ & Saturation pressure over ice (flat surface) & $\mathrm{Pa}$ \\
\hline$p_{\mathrm{sg}}, p_{\mathrm{sn}}$ & Saturation pressure, grains and necks & $\mathrm{Pa}$ \\
\hline & Viscous dissipation function & $\mathrm{s}^{-2}$ \\
\hline$q_{\mathrm{i} \leftrightarrow \mathrm{a}}^{\prime \prime}$ & $\begin{array}{l}\text { Heat flux across interfacial layer per surface } \\
\text { area }\end{array}$ & $\mathrm{W} \mathrm{m}^{-2}$ \\
\hline$Q_{\mathrm{i}}, Q_{\mathrm{a}}$ & Heat-flux ice matrix and pore air & $\mathrm{W}$ \\
\hline$R$ & Gas constant & $\mathrm{J} \mathrm{mol}^{-1} \mathrm{~K}^{-1}$ \\
\hline$\rho_{\mathrm{a}}, \rho_{\mathrm{v}}$ & Densities of dry air and water vapor & $\mathrm{kg} \mathrm{m}^{-3}$ \\
\hline$\rho_{\mathrm{S}}$ & Density corresponding to $p_{\mathrm{s}}$ & $\mathrm{kg} \mathrm{m}^{-3}$ \\
\hline$\rho_{\mathrm{sg}}, \rho_{\mathrm{sn}}$ & Density corresponding to $p_{\mathrm{sg}}, p_{\mathrm{sn}}$ & $\mathrm{kg} \mathrm{m}^{-3}$ \\
\hline$\sigma$ & $\begin{array}{l}\text { Surface energy or tension } \\
\left(\sigma=0.109 \mathrm{~N} \mathrm{~m}^{-1}\right)\end{array}$ & $\mathrm{Nm}^{-1}$ or $\mathrm{J} \mathrm{m}^{-2}$ \\
\hline$t$ & Time & s \\
\hline$\theta_{\mathrm{i}}, \theta_{\mathrm{a}}$ & $\begin{array}{l}\text { Volumetric components of ice and air, } \\
\theta_{\mathrm{i}}+\theta_{\mathrm{a}}=1\end{array}$ & \\
\hline$T_{\mathrm{i}}, T_{\mathrm{a}}, T_{\mathrm{v}}$ & Temperature of ice, air and vapor, $T_{\mathrm{a}}=T_{\mathrm{v}}$ & $\mathrm{K}$ \\
\hline$z$ & $\begin{array}{l}\text { Coordinate direction of the temperature } \\
\text { gradient }\end{array}$ & $\mathrm{m}$ \\
\hline
\end{tabular}

This procedure provides unambiguous information about form changes under the given thermodynamic constraints. These are interpreted within the framework of isothermaland temperature-gradient snow metamorphism.

\section{ENTROPY PRODUCTION IN SNOW}

We consider snow to be a porous medium consisting of ice (subscript i) and air (superscript a). The ice phase consists of grains which are bonded together to form a complicated and irregular but load-bearing ice skeleton. The ice skeleton is considered to be rigid. The pore air contains water vapor (supscript $\mathrm{v}$ ) which diffuses through the pore space of the granular skeleton. The diffusion rate is given by the mass flow rate of the air $\dot{m}_{\mathrm{a}}$; the density of the dry air is $\rho_{\mathrm{a}}$; the density of the water vapor $\rho_{\mathrm{v}}$. The partial vapor pressure is $p_{\mathrm{v}}$ and is related to the density via the ideal gas law. The water vapor has the same temperature as the dry air, $T_{\mathrm{v}}=T_{\mathrm{a}}$. We assume no free (fluid) water is present on the ice, i.e. the snow is dry. The temperature of the ice, $T_{\mathrm{i}}$, and that of the adjacent air, $T_{\mathrm{a}}$, are not in thermal equilibrium, $T_{\mathrm{i}} \neq T_{\mathrm{a}}$. In the presence of a temperature gradient, heat is being transferred in the ice (heat flux $Q_{\mathrm{i}}$ ) by conduction, and air (heat flux $Q_{\mathrm{a}}$ ) by conduction and advection. Temperature gradients are induced by meteorological forcing at the snow-cover surface; the heat flux and vapor fluxes are primarily in one direction, that is, in the direction of 


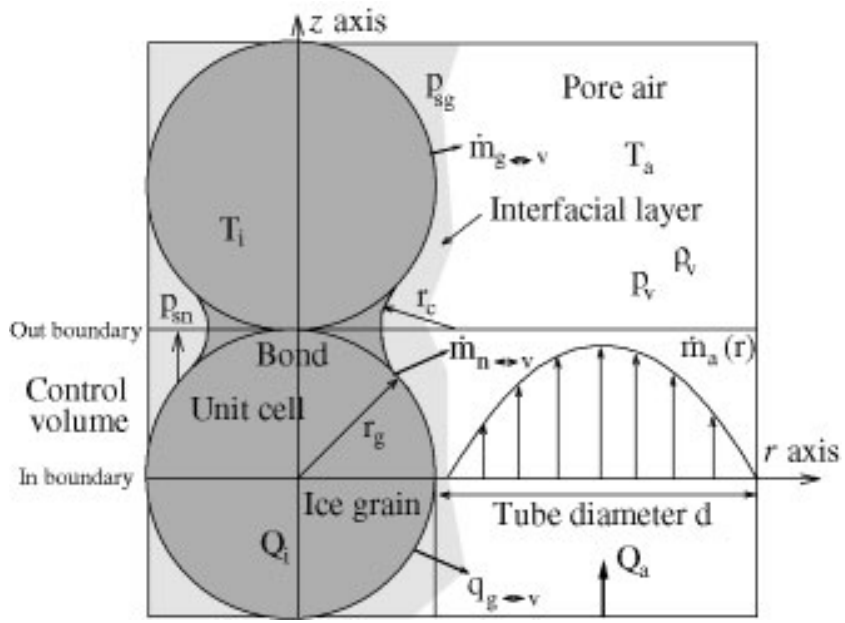

Fig. 2. Definition of thermodynamic and microstructural variables. Snow is defined as a porous medium of volumetric ice content $\theta_{\mathrm{i}}$ and volumetric air content $\theta_{\mathrm{a}}$. The grains have positive radius $r_{\mathrm{g}}$; the bonds have negative radius $r_{\mathrm{c}}$. The pore space is filled with dry air (subscript a) and water vapor ( subscript $\mathrm{v}$ ). The temperature of air and ice can differ. Surrounding the ice grains is a saturated boundary layer of pressure $p_{\mathrm{s}}$. The unit microstructural cell defines the control volume boundaries of our open thermodynamic system.

the temperature gradient (the $z$ direction). A list of the thermodynamic variables is provided in Table 1 .

At the interfacial ice-air boundary (subscript b), heat (free convection) and mass are exchanged between the ice lattice and pore air. The heat flux across the boundary per unit surface area we denote $q_{\mathrm{i} \leftrightarrow \mathrm{v}}^{\prime \prime}$; the mass flux across the boundary per unit surface area we denote $\dot{m}_{\mathrm{i} \leftrightarrow \mathrm{v}}^{\prime \prime}$. (The double prime denotes a quantity per unit area; a triple prime a quantity per unit volume.) The interfacial boundary is saturated with water vapor (saturation pressure $p_{\mathrm{s}}$, concentration density $\rho_{\mathrm{s}}$ ) which is maintained by sublimation or deposition processes from or to the ice surface. The heat flux across the interfacial boundary is driven by the temperature difference between the ice and air, $T_{\mathrm{i}}-T_{\mathrm{a}}$; the mass flux by the density difference, $\rho_{\mathrm{s}}-\rho_{\mathrm{v}}$. The layer has an unknown width. A schematic representation of this system is shown in Figure 2.

In summary, we consider a volume of snow to be an open thermodynamic system undergoing both heat and mass transfer. Due to symmetry, we chose the control volume such that it contains half an ice grain and half a bond (see Fig. 2). The control volume contains both ice and air. The relationship between grain-size and pore diameter is found by imposing the volumetric constraint $\theta_{\mathrm{i}}+\theta_{\mathrm{a}}=1$, where $\theta$ is the volumetric fraction of a component.

For this open system, the second law of thermodynamics can be stated as (Bejan, 1997):

$$
\dot{S}=\underbrace{\left[\frac{\mathrm{d} S_{\mathrm{b}}}{\mathrm{d} t}\right]}_{\text {interface }}-\underbrace{\left[\frac{Q_{\mathrm{i}}}{T_{\mathrm{i}}}+\frac{Q_{\mathrm{a}}}{T_{\mathrm{a}}}\right]}_{\text {conduction }}+\underbrace{\left[\sum_{\text {out }} \dot{m}_{\mathrm{a}} s-\sum_{\text {in }} \dot{m}_{\mathrm{a}} s\right]}_{\text {mass flow }} \geq 0,
$$

where $\dot{S}$ is the total entropy production, and $s$ the entropy density $\left(\mathrm{J} \mathrm{K}^{-1} \mathrm{~kg}^{-1}\right)$. The first term in square brackets is the rate of entropy accumulation inside the control volume due to interfacial boundary heat and mass transfer, $\dot{S}_{\mathrm{b}}$; the sec-
Table 2. Entropy variables. The subscripts are: $\mathrm{g}=$ grain, $\mathrm{n}=$ neck, $\mathrm{b}=$ interfacial mass transfer, $\mathrm{h}=$ interfacial heat transfer, $\mathrm{k}=$ conductivity, $\mathrm{f}=$ airflow. A triple prime denotes a quantity per unit volume

\begin{tabular}{|c|c|}
\hline Entropy density & $\mathrm{J} \mathrm{K}^{-1} \mathrm{~kg}^{-1}$ \\
\hline intropy production in control volume & $\mathrm{W} \mathrm{K}^{-1}$ \\
\hline $\begin{array}{l}\text { Entropy production in control volume in ice } \\
\text { lattice }\end{array}$ & $\mathrm{W} \mathrm{K}^{-1}$ \\
\hline Entropy production in control volume in pore air & $\mathrm{W} \mathrm{K}^{-1}$ \\
\hline $\begin{array}{l}\text { Entropy production in control volume in } \\
\text { interfacial layer }\end{array}$ & $\mathrm{W} \mathrm{K}^{-1}$ \\
\hline $\begin{array}{l}\text { Entropy production interfacial heat transfer per } \\
\text { unit volume }\end{array}$ & $\mathrm{W} \mathrm{K}{ }^{-1} \mathrm{~m}^{-3}$ \\
\hline $\begin{array}{l}\text { Entropy production interfacial mass-transfer } \\
\text { grains, per unit volume }\end{array}$ & $\mathrm{W} \mathrm{K}^{-1} \mathrm{~m}^{-3}$ \\
\hline $\begin{array}{l}\text { Entropy production interfacial mass-transfer } \\
\text { necks, per unit volume }\end{array}$ & $\mathrm{W} \mathrm{K}^{-1} \mathrm{~m}^{-3}$ \\
\hline $\begin{array}{l}\text { Entropy production conductive heat-transfer ice, } \\
\text { per unit volume }\end{array}$ & $\mathrm{W} \mathrm{K}{ }^{-1} \mathrm{~m}^{-3}$ \\
\hline $\begin{array}{l}\text { Entropy production conductive heat-transfer air, } \\
\text { per unit volume }\end{array}$ & $\mathrm{W} \mathrm{K}^{-1} \mathrm{~m}^{-3}$ \\
\hline $\begin{array}{l}\text { Entropy production mass-transfer air, per unit } \\
\text { volume }\end{array}$ & $\mathrm{W} \mathrm{K}^{-1} \mathrm{~m}^{-3}$ \\
\hline
\end{tabular}

ond term in brackets is the entropy transfer due to heat conduction in the ice and air; the third term in brackets is the net entropy flow rate out of the control volume via mass flow in the pore space. The entropy variables are listed in Table 2.

The entropy production per unit volume $\dot{S}_{\mathrm{bh}}^{\prime \prime \prime}$ due to the heat flux $q_{\mathrm{i} \leftrightarrow \mathrm{a}}^{\prime \prime}$ across the interfacial boundary is given by (Bejan, 1996):

$$
\dot{S}_{\mathrm{bh}}^{\prime \prime \prime}=\left(q_{\mathrm{i} \leftrightarrow \mathrm{a}}^{\prime \prime} A_{\mathrm{s}}\right) \frac{T_{\mathrm{i}}-T_{\mathrm{a}}}{T_{\mathrm{a}} T_{\mathrm{i}}},
$$

where $A_{\mathrm{s}}$ is the specific surface area of the boundary $\left(\mathrm{m}^{2} \mathrm{~m}^{-3}\right)$, in this case the total surface area of the interface within the control volume. The entropy generation is positive so long as the temperature difference exists. (If $T_{\mathrm{a}}>T_{\mathrm{i}}$ then the sign of the heat flux $q_{\mathrm{i} \leftrightarrow \mathrm{v}}^{\prime \prime}$ is negative.)

The entropy production per unit volume due to the mass flux across the interfacial layer over a grain $\dot{m}_{\mathrm{g} \leftrightarrow \mathrm{v}}^{\prime \prime}$ and necks $\dot{m}_{\mathrm{n} \leftrightarrow \mathrm{v}}^{\prime \prime}$ of the control volume is given by (Bejan, 1996)

$$
\dot{S}_{\mathrm{bg}}^{\prime \prime \prime}=\frac{\dot{m}_{\mathrm{g} \leftrightarrow \mathrm{v}}^{\prime \prime}}{\rho_{\mathrm{v}} T_{\mathrm{v}}}(-\operatorname{grad} p)
$$

and

$$
\dot{S}_{\mathrm{bn}}^{\prime \prime \prime}=\frac{\dot{m}_{\mathrm{n} \leftrightarrow \mathrm{v}}^{\prime \prime}}{\rho_{\mathrm{v}} T_{\mathrm{v}}}(-\operatorname{grad} p)
$$

respectively. Both expressions are required since the curvature of the grains and necks differ, meaning that both the mass flux and pressure gradient across the interfacial layer differ and must be considered separately. In summary, the total entropy accumulation within the control volume (the first part of Equation (1) per unit volume) is

$$
\dot{S}_{\mathrm{b}}^{\prime \prime \prime}=\dot{S}_{\mathrm{bh}}^{\prime \prime \prime}+\dot{S}_{\mathrm{bg}}^{\prime \prime \prime}+\dot{S}_{\mathrm{bn}}^{\prime \prime \prime}
$$

The entropy generation due to heat conduction across the control-volume boundaries in the ice and air is (Bejan, 1996):

$$
\dot{S}_{\mathrm{ik}}^{\prime \prime \prime}=\frac{k_{\mathrm{i}}}{T_{\mathrm{i}}^{2}}\left(\frac{\partial T_{\mathrm{i}}}{\partial z}\right)^{2}
$$


Table 3. Nomenclature of microstructural variables. The subscripts are: $\mathrm{i}=$ ice, $\mathrm{a}=$ air, $\mathrm{g}=$ grain, $\mathrm{n}=$ neck. The var ables are depicted in Figures 2 and 3

\begin{tabular}{lll}
\hline$V_{\mathrm{n}}$ & Ice volume of neck & $\mathrm{m}^{3}$ \\
$V_{\mathrm{g}}$ & Ice volume of grain & $\mathrm{m}^{3}$ \\
$V_{\mathrm{i}}$ & Total ice volume (in the control volume) & $\mathrm{m}^{3}$ \\
$V_{\mathrm{a}}$ & Total air volume (in the control volume) & $\mathrm{m}^{3}$ \\
$V_{\mathrm{t}}$ & Control volume & $\mathrm{m}^{3}$ \\
$A_{\mathrm{n}}$ & Surface area of necks & $\mathrm{m}^{2}$ \\
$A_{\mathrm{g}}$ & Surface area of grains & $\mathrm{m}^{2}$ \\
$l_{\mathrm{n}}$ & Neck length & $\mathrm{m}$ \\
$r_{\mathrm{n}}$ & Inner (smaller) radius of neck & $\mathrm{m}$ \\
$r_{\mathrm{g}}$ & Radius of grain & $\mathrm{m}$ \\
$r_{\mathrm{b}}$ & Outer (larger) radius of neck & $\mathrm{m}$ \\
$r_{\mathrm{c}}$ & Neck curvature radius & $\mathrm{m}$ \\
$\alpha$ & Neck angle & $\mathrm{rad}$ \\
\hline
\end{tabular}

and

$$
\dot{S}_{\mathrm{ak}}^{\prime \prime \prime}=\frac{k_{\mathrm{a}}}{T_{\mathrm{a}}^{2}}\left(\frac{\partial T_{\mathrm{a}}}{\partial z}\right)^{2},
$$

where $k_{\mathrm{i}}$ and $k_{\mathrm{a}}$ are the thermal conductivities of ice and air, respectively. The entropy generation in the pore space per unit volume, due to the net entropy flow rate out of the control volume via mass flow, is (Bejan, 1996)

$$
\dot{S}_{\mathrm{af}}^{\prime \prime \prime}=\frac{\mu}{T_{\mathrm{a}}} \Phi,
$$

where $\mu$ is the viscosity of air and $\Phi$ is the viscous dissipation function. This defines the third term in the statement of the second law, Equation (1), per unit volume.

The specific total entropy production $\dot{S}^{\prime \prime \prime}$ is the sum of the entropy production in the ice, interfacial boundary layer and pore air,

$$
\dot{S}^{\prime \prime \prime}=\dot{S}_{\mathrm{i}}^{\prime \prime \prime}+\dot{S}_{\mathrm{b}}^{\prime \prime \prime}+\dot{S}_{\mathrm{a}}^{\prime \prime \prime} .
$$

In the above derivation, several assumptions were made that were not explicitly mentioned. Is entropy production additive? In principle, entropy production is not additive because the processes are not independent, as given by Onsager's reciprocity relations (Bejan, 1997). By adding the entropy production terms, we are implicitly assuming, for instance, that Soret and Dufour diffusion effects can be neglected. This implies that the cross-diagonal terms of Onsager's relations are zero. Another assumption is that surface tension effects are reversible and therefore do not contribute to entropy production. Two other entropy producing processes we did not include in our model are radiation and viscous (irreversible) deformation. We assume that the ice matrix is rigid.

\section{THE MIGROSTRUGTURAL MODEL}

Consider Figure 1 which shows a thin cross-section of a snow sample. The sample consists of well-rounded grains which are bonded together at necks. Note that both positive (concave) and negative (convex) curvatures exist in the sample. Furthermore, the curvature radius of the grains is in general larger than the grain radius. In the following, we do not attempt to model the complex geometric arrangement of grains. Rather we concentrate on the basic microstructural elements: grains and necks. Thus, the microstructural model consists of two spherical grains of radius $r_{\mathrm{g}}$ (Fig. 2).

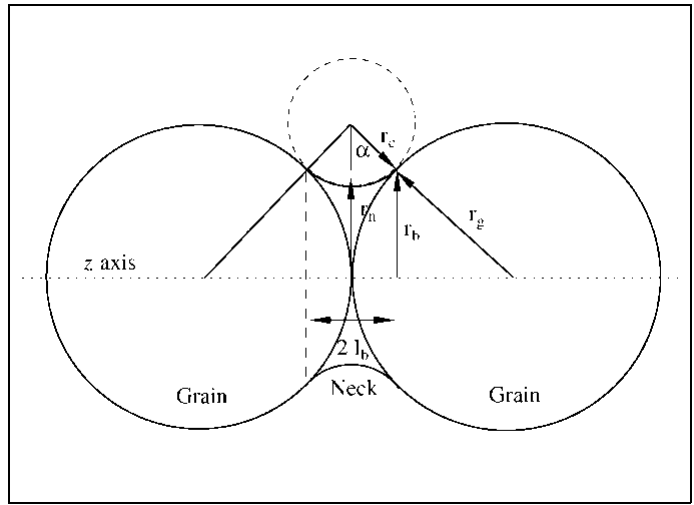

Fig. 3. Definition of microstructural variables. Spherical ice grains of radius $r_{\mathrm{g}}$ are connected by bonds of radius $r_{\mathrm{b}}$. The radius of curvature of the bonds is $r_{\mathrm{c}}$. The model consists of only two free parameters, $r_{\mathrm{g}}$ and $r_{\mathrm{c}}$. $\alpha$ is half the bond angle.

The distance between grain centers is $2 r_{\mathrm{g}}$. A concaveshaped neck is constructed by revolving the bond arc length of radius $r_{\mathrm{c}}$ around the axis of grain contact, the $z$ axis. Due to symmetry, only the section consisting of a half-neck (of length $l_{\mathrm{n}}$ ) and half-grain (of radius $r_{\mathrm{g}}$ ) is considered in the entropy minimization analysis. The important feature of this model is that the geometry is defined by only two parameters, the grain radius $r_{\mathrm{g}}$ and the neck radius $r_{\mathrm{c}}$. The model has been employed by other authors to describe snow metamorphism (Lehning and others, 2002). Other snow types (e.g. dendritic new snow) would require a different microstructural model. A complete list of the microstructural variables is contained in Table 3 .

The relationship between the grain radius $r_{\mathrm{g}}$ and neck radius $r_{\mathrm{c}}$ can be expressed in terms of the angle $\alpha$ (see Fig. 3)

$$
r_{\mathrm{g}}=r_{\mathrm{c}}\left[\frac{\sin (\alpha)}{1-\sin (\alpha)}\right] \text {. }
$$

The neck radius $r_{\mathrm{b}}$ is

$$
r_{\mathrm{b}}=r_{\mathrm{g}} \cos (\alpha) \text {. }
$$

The cross-sectional neck radius $r_{\mathrm{b}}$ should not be confused with the neck curvature radius $r_{\mathrm{c}}$ which is used to define the vapor pressure near the neck surface. The cross-sectional radius of the neck at the point of grain contact is denoted $r_{\mathrm{n}}$ and can be found by solving the following quadratic equation:

$$
r_{\mathrm{g}}^{2}+\left(r_{\mathrm{c}}+r_{\mathrm{n}}\right)^{2}=\left(r_{\mathrm{g}}+r_{\mathrm{c}}\right)^{2} .
$$

The length of the neck is

$$
l_{\mathrm{n}}=r_{\mathrm{c}} \sin (\alpha)=r_{\mathrm{g}}[1-\sin (\alpha)]=\frac{r_{\mathrm{g}} r_{\mathrm{c}}}{r_{\mathrm{g}}+r_{\mathrm{c}}} .
$$

The surface area of the ice, $A_{\mathrm{s}}$, is given by the sum of the neck surface area

$$
A_{\mathrm{n}}=2 \pi r_{\mathrm{c}}\left(\alpha r_{\mathrm{n}}+\alpha r_{\mathrm{c}}-l_{\mathrm{n}}\right)
$$

and the grain surface area

$$
A_{\mathrm{g}}=2 \pi r_{\mathrm{g}}\left(r_{\mathrm{g}}-l_{\mathrm{n}}\right) .
$$

Likewise, the volume of the ice is given by the sum of the neck volume

$$
V_{\mathrm{n}}=4 \pi^{2} r_{\mathrm{c}}\left[\frac{\left(\alpha r_{\mathrm{n}}+\alpha r_{\mathrm{c}}-l_{\mathrm{n}}\right)^{2}}{\alpha}\right]
$$


and the grain volume

$$
V_{\mathrm{g}}=\left[\frac{2}{3} \pi r_{\mathrm{g}}^{3}\right]-\left[\frac{\pi l_{\mathrm{n}}^{2}}{3}\left(3 r_{\mathrm{g}}-l_{\mathrm{n}}\right)\right] .
$$

The total ice volume is

$$
V_{\mathrm{i}}=V_{\mathrm{g}}+V_{\mathrm{n}} .
$$

The total volume, $V_{\mathrm{t}}$, is the sum of the ice and air volumes

$$
V_{\mathrm{t}}=V_{\mathrm{a}}+V_{\mathrm{i}}=V_{\mathrm{i}}\left(1+\frac{\theta_{\mathrm{a}}}{\theta_{\mathrm{i}}}\right),
$$

where $\theta_{\mathrm{i}}$ and $\theta_{\mathrm{a}}$ are the volumetric fractions of ice and air, respectively.

\section{ENTROPY PRODUGTION COMPONENTS}

\subsection{Interfacial heat and mass transfer}

The vapor saturation pressure in the interfacial layer over the ice grain is denoted $p_{\mathrm{sg}}$ and given by the vapor equation of Laplace

$$
p_{\mathrm{sg}}=\bar{p}_{\mathrm{s}}+\frac{2 \sigma}{r_{\mathrm{g}}},
$$

where $\bar{p}_{\mathrm{s}}$ is saturation pressure over a flat surface and $\sigma$ is the surface tension. The interfacial layer over the ice is assumed to be saturated at temperature $T_{\mathrm{i}}$, and thus the water-vapor pressure over a flat ice surface, $\bar{p}_{\mathrm{s}}$, is found from the wellknown Clausius-Clapeyron relation. Similarly, the vapor saturation pressure over the neck is denoted $p_{\mathrm{sn}}$ and approximately given by

$$
p_{\mathrm{sn}}=\bar{p}_{\mathrm{s}}+\sigma\left(\frac{1}{r_{\mathrm{n}}}-\frac{1}{r_{\mathrm{c}}}\right) .
$$

Note that the bond, unlike the grain, possesses both convex (radius $r_{\mathrm{n}}$ ) and concave (radius $r_{\mathrm{c}}$ ) surfaces. The air is assumed to be saturated at vapor temperature $T_{\mathrm{v}}$, and thus the water-vapor pressure in the air, $p_{\mathrm{v}}$, can likewise be determined from the Clausius-Clapeyron relation.

The mass exchange from the ice to the surrounding pore space is given by the difference in vapor concentration between the boundary layer and air (Incropera and Dewitt, 2002). Specifically, the mass-transfer rate across the interfacial grain layer is

$$
\dot{m}_{\mathrm{g} \leftrightarrow \mathrm{v}}^{\prime \prime}=h_{\mathrm{m}}\left(\rho_{\mathrm{sg}}-\rho_{\mathrm{v}}\right),
$$

where $h_{\mathrm{m}}$ is the interfacial mass-transfer coefficient, $\rho_{\mathrm{sg}}$ is the vapor density of the interfacial layer and $\rho_{\mathrm{v}}$ is the vapor density of the pore space. Assuming an ideal gas, the masstransfer rate can be expressed in terms of the pressure difference (Incropera and DeWitt, 2002)

$$
\dot{m}_{\mathrm{g} \leftrightarrow \mathrm{v}}^{\prime \prime}=\tilde{h}_{\mathrm{m}}\left(p_{\mathrm{sg}}-p_{\mathrm{v}}\right)=\tilde{h}_{\mathrm{m}}\left(\Delta p+\frac{2 \sigma}{r_{\mathrm{g}}}\right),
$$

where the interfacial mass-transport coefficient $\tilde{h}_{\mathrm{m}}$ is related to $h_{\mathrm{m}}$ according to

$$
\tilde{h}_{\mathrm{m}}=\frac{h_{\mathrm{m}} M_{\mathrm{v}}}{R T_{\mathrm{v}}} .
$$

$M_{\mathrm{v}}$ is the molecular mass of water vapor $\left(M_{\mathrm{v}}=\right.$ $1.80 \mathrm{~kg} \mathrm{~mol}^{-1}$ ) and $R$ is the molar gas constant. The pressure difference $\Delta p$ is defined as

$$
\Delta p=\bar{p}_{\mathrm{s}}-p_{\mathrm{v}},
$$

that is, the part of the pressure difference between the interfacial layer and air which is independent of curvature effects. In a similar manner, the mass transfer over the neck surface can be found:

$$
\dot{m}_{\mathrm{n} \leftrightarrow \mathrm{v}}^{\prime \prime}=\tilde{h}_{\mathrm{m}}\left(p_{\mathrm{sb}}-p_{\mathrm{v}}\right)=\tilde{h}_{\mathrm{m}}\left[\Delta p+\sigma\left(\frac{1}{r_{\mathrm{n}}}-\frac{1}{r_{\mathrm{c}}}\right)\right] .
$$

Note that $\dot{m}_{\mathrm{g} \leftrightarrow \mathrm{v}}$ and $\dot{m}_{\mathrm{n} \leftrightarrow \mathrm{v}}$ are positive when mass sublimates from the ice. In order to find the total entropy production in the control volume, Equations (3) and (4) must be integrated over the volume. We find the total entropy production rates for the grains and necks:

$$
\begin{gathered}
\dot{S}_{\mathrm{bg}}=\frac{\tilde{h}_{\mathrm{m}} A_{\mathrm{g}}}{\rho_{\mathrm{v}} T_{\mathrm{v}}}\left(\Delta p+\frac{2 \sigma}{r_{\mathrm{g}}}\right)^{2} \\
\dot{S}_{\mathrm{bn}}=\frac{\tilde{h}_{\mathrm{m}} A_{\mathrm{n}}}{\rho_{\mathrm{v}} T_{\mathrm{v}}}\left[\Delta p+\sigma\left(\frac{1}{r_{\mathrm{n}}}-\frac{1}{r_{\mathrm{c}}}\right)\right]^{2} .
\end{gathered}
$$

The interfacial heat flux between the ice lattice and pore space can be given by

$$
q_{\mathrm{i} \leftrightarrow \mathrm{v}}^{\prime \prime}=h\left(T_{\mathrm{i}}-T_{\mathrm{a}}\right),
$$

where $h$ is the local convection coefficient (Incropera and DeWitt, 2002). The total entropy production per unit cell for this process can likewise be found by integrating Equation (2) over the total boundary area:

$$
\dot{S}_{\mathrm{bh}}=h\left(A_{\mathrm{g}}+A_{\mathrm{n}}\right) \frac{\left(T_{\mathrm{i}}-T_{\mathrm{a}}\right)^{2}}{T_{\mathrm{a}} T_{\mathrm{i}}} .
$$

Kaviany (1995) provides a relationship between the dimensionless Nusselt number $\left(\mathrm{Nu}=\left(2 h r_{\mathrm{g}} / k_{\mathrm{a}}\right)\right)$ and air speed based on packed-bed experiments with spherical particles. For low Reynolds number, $\mathrm{Nu} \approx 2$. Thus, the local heat convection coefficient can be approximated,

$$
h=\frac{k_{\mathrm{a}}}{r_{\mathrm{g}}} .
$$

This formula is based on an evaluation of both steady-state and transient packed-bed experiments, for a wide range of Reynolds number. It should be noted that few if any data exist for the interfacial heat-transfer coefficient for snow and that at low Reynolds number the above equation has not been experimentally verified (Kaviany, 1995).

The relationship between the convection heat-transfer coefficient and the mass-transfer coefficient can be found in Incropera and DeWitt (2002). We make the following approximation:

$$
\frac{h}{h_{\mathrm{m}}}=\rho c \mathrm{Le}^{1-n} \approx 10^{3},
$$

where $\rho \approx 1 \mathrm{~kg} \mathrm{~m}^{-3}$ is the density of air, $c$ is the specific heat capacity of air $c \approx 1000 \mathrm{~J} \mathrm{~kg}^{-1} \mathrm{~K}^{-1}$, and $\mathrm{Le}^{1-n} \approx 1$ is the dimensionless Lewis number, the ratio of thermal to mass diffusivities (see Incropera and DeWitt, 2002).

\subsection{Heat conduction}

The entropy produced in the control volume by heat conduction in the ice and pore air is (Bejan, 1996)

$$
\dot{S}_{\mathrm{ik}}=\frac{k_{\mathrm{i}}}{T_{\mathrm{i}}^{2}}\left(\frac{\partial T_{\mathrm{i}}}{\partial z}\right)^{2} V_{\mathrm{i}},
$$

and

$$
\dot{S}_{\mathrm{ak}}=\frac{k_{\mathrm{a}}}{T_{\mathrm{a}}^{2}}\left(\frac{\partial T_{\mathrm{a}}}{\partial z}\right)^{2} V_{\mathrm{a}} .
$$

We are assuming that the conductivities, $k_{\mathrm{i}}$ and $k_{\mathrm{a}}$, are independent of $z$. 

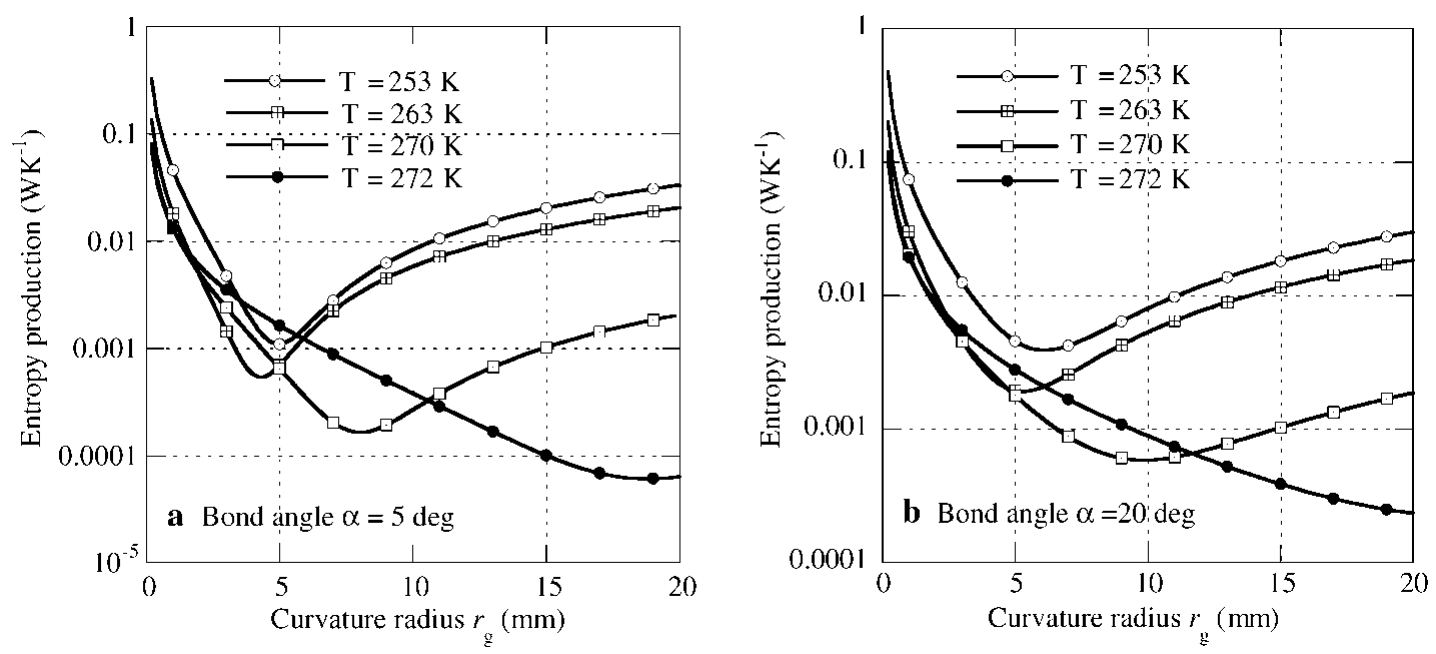

Fig. 4. Entropy production as a function of grain curvature for different temperatures. (a) $\alpha=5^{\circ}$ and (b) $\alpha=20^{\circ}$. Production minima are located at large curvature radii with increasing temperature. At $T=272 \mathrm{~K}$ the entropy production minimum is at a very large curvature radius, not seen on the graph.

\subsection{Air current in pore space}

Air movement in snow is in the laminar, creeping flow regime. Reynolds numbers are small, $\operatorname{Re}<10$. For this flow regime, various porous-media airflow models can be applied (Kaviany, 1995). Buser and Good (1987) found that a capillary tube model fits the experimental data of Shimuzu (1970) as well as their own data. The entropy production in tubes in the laminar flow regime has been determined by Bejan (1996). For Hagen-Poiseuille flow the velocity distribution in the pore space varies parabolically (Fig. 2), according to,

$$
u_{\mathrm{a}}(r)=\frac{3}{2} u_{\text {avg }}\left[1-\left(\frac{r}{d / 2}\right)^{2}\right],
$$

where $u_{\text {avg }}$ is the average air velocity and $d$ the tube diameter. In a Hagen-Poiseuille flow model, the flow velocity tangential to the ice surface $(r=d / 2)$ is zero and reaches a maximum at the tube middle, $r=0$. The entropy production per unit volume at any position $r$ for this case is (Bejan, 1996)

$$
\dot{S}_{\mathrm{a}}^{\prime \prime \prime}=\frac{\mu}{T_{\mathrm{a}}} \Phi=36 \frac{\mu}{T_{\mathrm{a}}}\left(\frac{u_{\mathrm{avg}}}{d}\right)^{2}\left(\frac{r}{d / 2}\right)^{2},
$$

where $\mu$ is the viscosity of air $\left(\mu=2.2 \times 10^{-5} \mathrm{~kg} \mathrm{~m}^{-1} \mathrm{~s}^{-1}\right)$. For our purposes, the entropy production in the control volume must be found by integrating the above equation over the length $\left(r_{\mathrm{g}}\right)$ and tube area. We find:

$$
\dot{S}_{\mathrm{a}}=\frac{9}{2} \pi u_{\mathrm{avg}}^{2} r_{\mathrm{g}}\left(\frac{\mu}{T_{\mathrm{a}}}\right) .
$$

Typical average velocities are $u_{\text {avg }} \approx 1.0 \times 10^{-6} \mathrm{~m} \mathrm{~s}^{-1}$ arising from pressure differences induced by temperature gradients. Higher values due to wind pumping at the surface of the snow cover can be found, but it is estimated that these values are seldom over $u_{\text {avg }}<1.0 \times 10^{-4} \mathrm{~m} \mathrm{~s}^{-1}$.

\section{ENTROPY PRODUCTION MINIMIZATION}

The total entropy production in the control volume is given by the sum of the entropy production in the ice, due to heat conduction (Equation (33)),

$$
\dot{S}_{\mathrm{i}}=\frac{k_{\mathrm{i}}}{T_{\mathrm{i}}^{2}}\left(\frac{\partial T_{\mathrm{i}}}{\partial z}\right)^{2} V_{\mathrm{i}}
$$

the interfacial layer, due to heat and mass transfer (from Equations (27), (28) and (30)),

$$
\begin{aligned}
\dot{S}_{\mathrm{b}}= & \frac{\tilde{h}_{\mathrm{m}} A_{\mathrm{g}}}{\rho_{\mathrm{v}} T_{\mathrm{v}}}\left(\Delta p+\frac{2 \sigma}{r_{\mathrm{g}}}\right)^{2}+\frac{\tilde{h}_{\mathrm{m}} A_{\mathrm{b}}}{\rho_{\mathrm{v}} T_{\mathrm{v}}}\left[\Delta p+\sigma\left(\frac{1}{r_{\mathrm{n}}}-\frac{1}{r_{\mathrm{c}}}\right)\right]^{2} \\
& +h\left(A_{\mathrm{g}}+A_{\mathrm{n}}\right) \frac{\left(T_{\mathrm{i}}-T_{\mathrm{a}}\right)^{2}}{T_{\mathrm{a}} T_{\mathrm{i}}}
\end{aligned}
$$

and, finally, the entropy production in the adjacent pore space, due to heat conduction and fluid friction (Equations (34) and (37)):

$$
\dot{S}_{\mathrm{a}}=\frac{k_{\mathrm{a}}}{T_{\mathrm{a}}^{2}}\left(\frac{\partial T_{\mathrm{a}}}{\partial z}\right)^{2} V_{\mathrm{a}}+\frac{9}{2} \pi u_{\mathrm{avg}}^{2} r_{\mathrm{g}}\left(\frac{\mu}{T_{\mathrm{a}}}\right) .
$$

Given the air and ice temperature, the temperature gradient and the pore air velocity, the total entropy production

$$
\dot{S}=\dot{S}_{\mathrm{i}}+\dot{S}_{\mathrm{b}}+\dot{S}_{\mathrm{a}}
$$

can be expressed in terms of the grain radius, $r_{\mathrm{g}}$, assuming a bond angle $\alpha$.

Figure 4 plots the total entropy production as a function of the grain curvature radius $r_{\mathrm{g}}$ for two bond angles (a) $\alpha=$ $5^{\circ}$ and (b) $\alpha=20^{\circ}$. The plot depicts the entropy production at four different temperatures varying between $T=253 \mathrm{~K}$ and $T=272 \mathrm{~K}$. The system is placed in thermal equilibrium, i.e. $T=T_{\mathrm{a}}=T_{\mathrm{i}}$; no temperature difference exists between the ice and air. Thus, the figure shows the entropy production minima as a function of varying isothermal temperature. At lower temperatures, the mimima are located at larger grain radii. In addition, the minima at lower temperatures are associated with higher entropy production levels. Note that when the system reaches an isothermal state near $T=272 \mathrm{~K}$, a small change in equilibrium temperature influences the entropy production significantly. The change in entropy production from $T=$ $253 \mathrm{~K}$ to $T=263 \mathrm{~K}$ is small in comparison to the change from $T=263 \mathrm{~K}$ to $T=270 \mathrm{~K}$. At $T=272 \mathrm{~K}$ the entropy production minimum is at a very large curvature radius, not seen on the graph. 


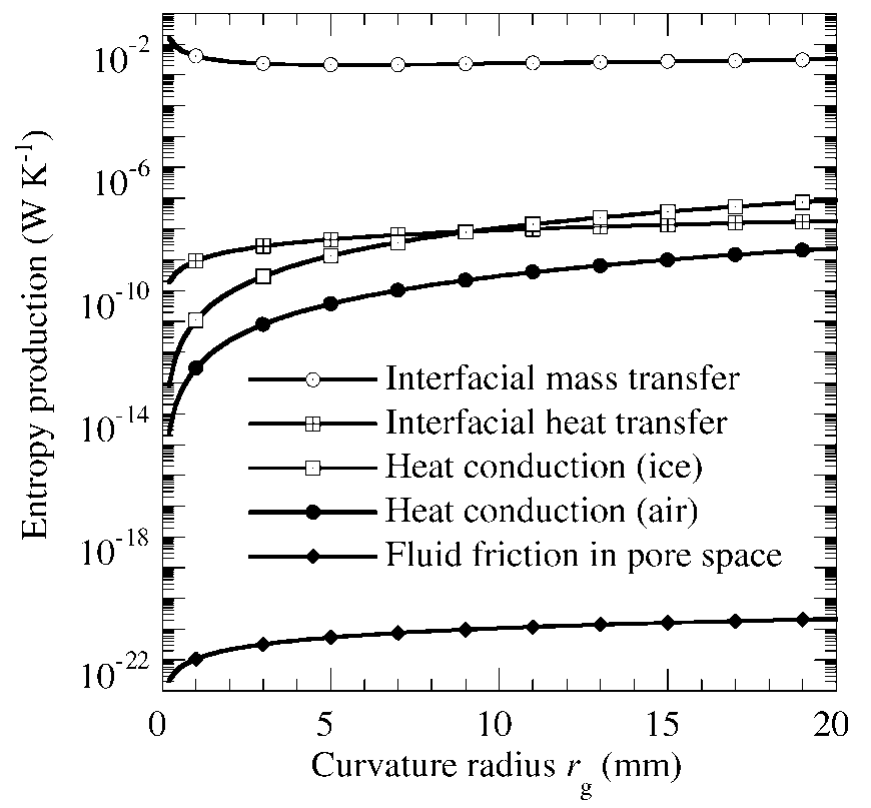

Fig. 5. Components of entropy production. Ice temperature $T_{\mathrm{i}}$ $=265 \mathrm{~K}$; air temperature $T_{\mathrm{a}}=263 \mathrm{~K}$; air velocity $u_{\mathrm{a}}=1.0$ $\times 10^{-6}$; temperature gradient $\mathrm{d} T / \mathrm{d} z=10 \mathrm{Km}^{-1}$. The plot depicts the importance of interfacial mass transfer in the total entropy production.

Figure 5 displays the contributions to the total entropy production, classified according to the different thermodynamical processes: interfacial mass transport, interfacial heat transport, heat conduction in the ice and air and fluid friction. The graph shows that the primary producer of entropy is clearly interfacial mass transport (by a factor of 100 over convective heat transport). Entropy production due to fluid friction in the pore air is insignificant. Since snow metamorphism is defined as the process of mass change under thermodynamic actions, this result underscores the connection between entropy production and snow metamorphism.

\section{DISGUSSION OF RESULTS}

\subsection{Minimum entropy production at equilibrium temperatures (isothermal metamorphism)}

The isothermal temperature results depicted in Figure 4 can be visualized from a different perspective. As shown, the entropy production curve as a function of $r_{\mathrm{g}}$ contains a welldefined minimum. In order to find the grain radius at which the total entropy production is minimal, we solve

$$
\frac{\mathrm{d} \dot{S}}{\mathrm{~d} r_{\mathrm{g}}}=0 .
$$

The curvature radius at which entropy production is minimum for a defined thermodynamic state is termed the optimal curvature radius, $r_{\text {opt }}$. Figure 6 plots the optimal curvature radius as a function of the difference in temperature between the ice and air, $\Delta T=T_{\mathrm{i}}-T_{\mathrm{a}}$, for three different ice temperatures. The three curves intersect the $\Delta T=$ $0 \mathrm{~K}$ axis at three different locations. The colder the temperature, the smaller the curvature radius. This agrees with observations made by Marbouty (1980). Note also that the optimal curvature radius for the isothermal case is not the largest radius possible. Larger optimal curvature radii, for a

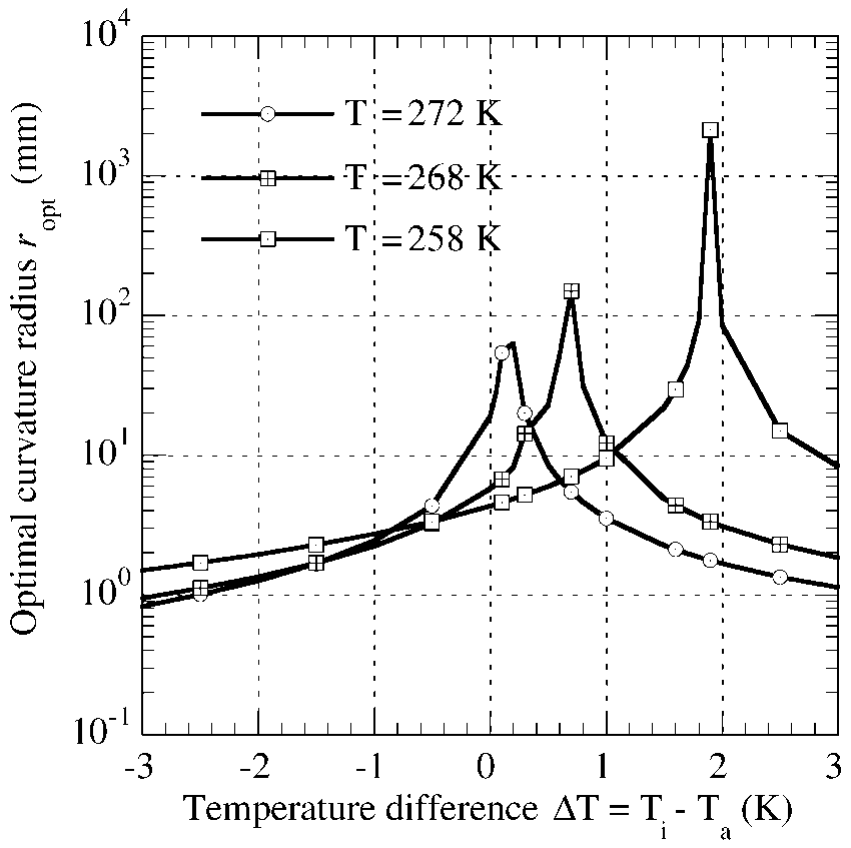

Fig. 6. Optimal grain curvature radius as a function of temperature difference. The maximum optimal radii do not occur on the $\Delta T=0^{\circ} \mathrm{C}$ isothermal axis. The lower the temperature the farther away the peaks are from the isothermal axis.

given ice and air temperature, are predicted when the temperature is higher in the ice than in the air.

The influence of bond size on entropy production is depicted in Figure 7a, which shows the entropy production for two different bond angles $\alpha=5^{\circ}$ and $\alpha=45^{\circ}$. Isothermal conditions were imposed on the ice and air, $T_{\mathrm{i}}=T_{\mathrm{a}}=$ $268 \mathrm{~K}$. The bond angle $\alpha$ influences the location of the minimum entropy production. Smaller bond angles induce smaller optimal curvature radii. Evidently, the geometry of the microstructural model plays an important role in the application of the principle of minimum entropy. Figure $7 \mathrm{~b}$ shows the influence of supersaturation (1.05\% of saturation) and partial saturation $(0.95 \%$ of saturation $)$ on the entropy production. The graph shows that $r_{\mathrm{opt}}$ is not sensitive to the state of saturation; however, the magnitude of the entropy production changes significantly.

\subsection{Minimum entropy production at non-equilibrium temperatures (temperature-gradient metamorphism)}

Several other important results can be ascertained from Figure 6. First, note that the optimal radius curves are not symmetric around the isothermal $\Delta T=0 \mathrm{~K}$ axis. The maximum radii for a given temperature are located to the right of the $\Delta T=0 \mathrm{~K}$ axis; that is, for $\Delta T>0 \mathrm{~K}$, or when the temperature in the ice is higher than the air temperature, $T_{\mathrm{i}}>T_{\mathrm{a}}$. The peaks are extremely sharp, meaning that slight changes in the thermodynamic state will produce significant changes in optimal curvature radius. Note also that the colder the ice temperature, the farther away the peaks are located from the $\Delta T=0 \mathrm{~K}$ axis. For example, for an ice temperature of $T_{\mathrm{i}}=258 \mathrm{~K}$, the maximum optimal radius is located at $\Delta T=2 \mathrm{~K}$; for a higher ice temperature $T_{\mathrm{i}}=$ $272 \mathrm{~K}$, the peak is located very near the $\Delta T=0 \mathrm{~K}$ axis. This result suggests that in order to obtain flat grains at low temperatures, a large temperature difference between the ice 

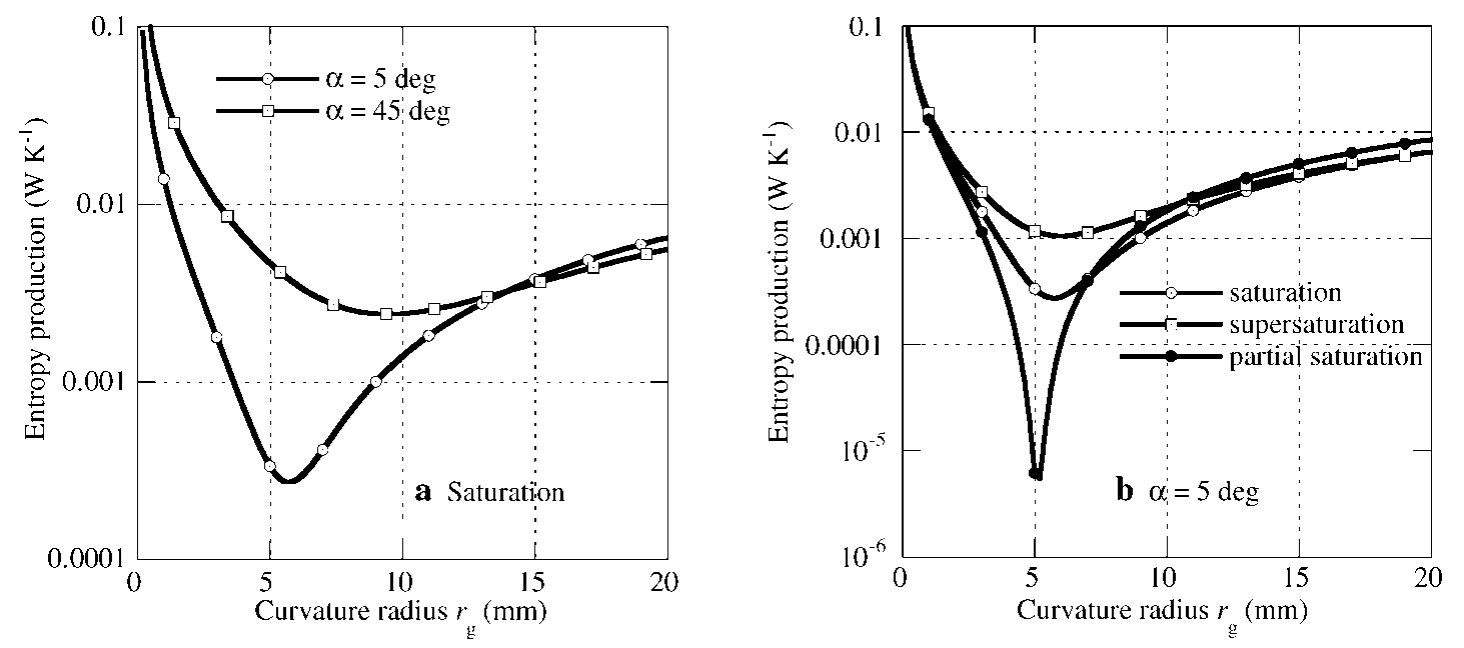

Fig. 7. (a) Entropy production for different bond configurations, $\alpha=5^{\circ}$ and $\alpha=45^{\circ}$. (b) Entropy production for different degrees of saturation, $\alpha=5^{\circ}$. Calculations assume isothermal conditions: $T_{\mathrm{i}}=T_{\mathrm{a}}=268 \mathrm{~K}$.

and air $\left(T_{\mathrm{i}}-T_{\mathrm{a}}\right)$ must be maintained. This will seldom occur since the energy transfer (convective heat exchanges) between the ice and air phases will ensure a state near $\Delta T=$ $0 \mathrm{~K}$. Thus, the theory of minimum entropy production predicts that very flat grains at colder temperatures are possible, but probably rare. Alternatively, at temperatures near $T_{\mathrm{i}}=273 \mathrm{~K}$, smaller temperature differences of the order $\approx 0.1 \mathrm{~K}$ are required to obtain the optimal curvature radius.

One way to induce and maintain temperature differences between the ice and air is to apply a temperature gradient $\mathrm{d} T / \mathrm{d} z$ to the system, a snow layer or the entire snowpack. This can be shown by considering the following very simple model in which the ice and air components of a control volume are divided into two parts as shown in Figure 8. The goal of the analysis is to find the steady-state temperature distribution in the ice, $T_{\mathrm{i}}(z)$, and air, $T_{\mathrm{a}}(z)$, when a

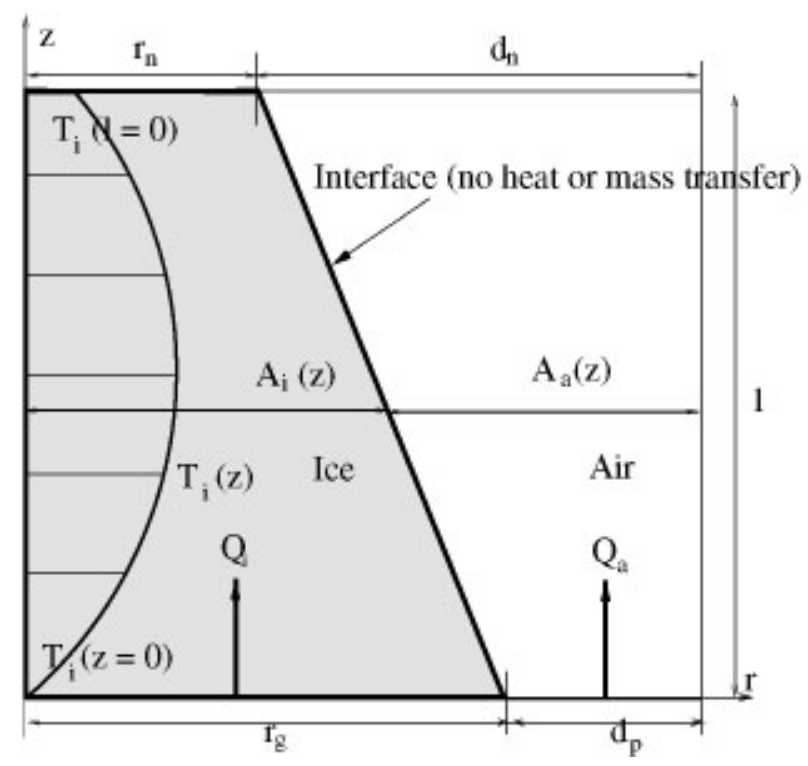

Fig. 8. A simple microstructural cell model consisting of ice and air. The ice is in the shape of a cone of length l with top radius $r_{\mathrm{n}}$ and bottom radius $r_{\mathrm{g}}$. The air is in the shape of an inverse cone with radii $d_{\mathrm{n}}$ and $d_{\mathrm{p}}$. No heat is transferred across the ice-air boundary. The model is used to demonstrate the temperature difference between the ice and air given a heat flux in the ice $Q_{\mathrm{i}}$ and air $Q_{\mathrm{a}}$. temperature gradient is applied. We are interested in the magnitude of the ice-air temperature difference $\Delta T(z)=T_{\mathrm{i}}(z)-T_{\mathrm{a}}(z)$. For simplicity, the ice part consists of a cone. The upper radius is the neck radius, $r_{\mathrm{n}}$; the lower radius is the grain radius $r_{\mathrm{g}}$. The temperature distribution in the cone is calculated disregarding surface heat and mass exchanges. For steady-state conditions, the heat flux is

$$
Q_{\mathrm{i}}=A_{\mathrm{i}}(z) k_{\mathrm{i}} \frac{\mathrm{d} T_{\mathrm{i}}}{\mathrm{d} z} .
$$

The temperature distribution at position $z$ is found from the above equation:

$$
T_{\mathrm{i}}(z)=T(0)+\frac{Q_{\mathrm{i}}}{k_{\mathrm{i}}} \int_{0}^{z} \frac{\mathrm{d} z}{A_{\mathrm{i}}(z)} .
$$

The cross-sectional area is

$$
A_{\mathrm{i}}(z)=\pi r^{2}(z)
$$

with

$$
r=r_{\mathrm{g}}-\left(\frac{r_{\mathrm{g}}-r_{\mathrm{n}}}{l}\right) z .
$$

The integral, Equation (44), can easily be evaluated (for this simple geometry):

$$
T_{\mathrm{i}}(z)=T(0)+\frac{Q_{\mathrm{i}}}{k_{\mathrm{i}} \pi} \frac{z l}{\left(r_{\mathrm{g}} l-z r_{\mathrm{g}}+z r_{\mathrm{n}}\right)} .
$$

The temperature difference between the upper $\left(z=r_{\mathrm{n}}\right)$ and lower $(z=0)$ cone surfaces can subsequently be found:

$$
T_{\mathrm{i}}\left(r_{\mathrm{g}}\right)-T(0)=-\frac{Q_{\mathrm{i}} l}{\pi k_{\mathrm{i}} r_{\mathrm{n}} r_{\mathrm{g}}} .
$$

For air, the same calculation procedures apply, substituting $d_{\mathrm{p}}$ for $r_{\mathrm{g}}$ and $d_{\mathrm{n}}$ for $r_{\mathrm{n}}$. The height of the microstructural cell is in both cases $l$.

An example calculation is presented in Figure 9. A temperature gradient of $100 \mathrm{~K} \mathrm{~m}^{-1}$ is applied over a cell of $1 \mathrm{~mm}$ length. The base temperature at $z=0$ is $268 \mathrm{~K}$; the neck temperature is $268.1 \mathrm{~K}$. The volumetric content of ice is $\theta_{\mathrm{i}}=0.3$. The grain radius is $r_{\mathrm{g}}=1 \mathrm{~mm}$; the neck radius is $r_{\mathrm{n}}=0.4 \mathrm{~mm}$. Figure $9 \mathrm{a}$ displays the temperature distribution in the ice and air over the cell length. Figure $9 \mathrm{~b}$ displays the temperature difference between the ice and air. The important fact to observe is that a temperature difference of $0.1 \mathrm{~K}$ over the length of the grain produces a maximum temperature difference of $0.03 \mathrm{~K}$ between the ice and air. More 

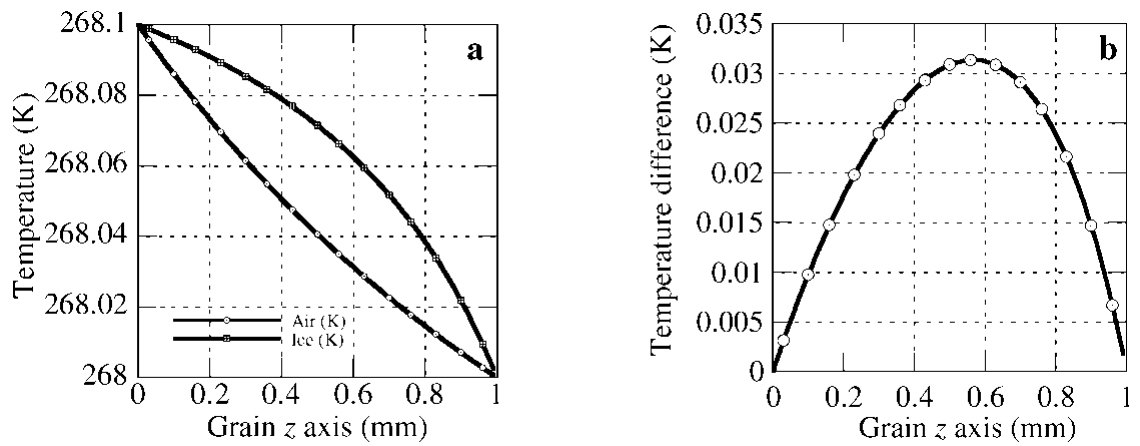

Fig. 9. A temperature gradient of $100 \mathrm{~K} \mathrm{~m}^{-1}$ is applied over a microstructural cell of $1 \mathrm{~mm}$ length. The base temperature at $z=0$ is $268 \mathrm{~K}$; the neck temperature is $268.1 \mathrm{~K}$. The volumetric content of ice is $\theta_{\mathrm{i}}=0.3$. The grain radius is $r_{\mathrm{g}}=1 \mathrm{~mm}$; the neck radius is $r_{\mathrm{n}}=0.4 \mathrm{~mm}$. (a) Temperature distribution in the ice and air over the cell length. (b) Temperature difference. The important fact to observe is that a temperature difference of $0.1 \mathrm{~K}$ over the length of the grain produces a maximum temperature difference of $0.03 \mathrm{~K}$ between the ice and air.

complicated and realistic geometries will strengthen this effect. If the bond and ice radius are equal, the temperature difference will vanish.

In summary, because the ice lattice consists of a non-uniform, irregular structure, global temperature gradients will induce local temperature differences between the ice and air. If the temperature of the ice lattice is $268 \mathrm{~K}<T_{\mathrm{i}}<$ $273 \mathrm{~K}$, these temperature differences must only be of the order $\Delta T<0.1 \mathrm{~K}$ to produce massive changes in the optimal curvature radius. The fact that larger temperature differences are required at colder temperatures agrees well with the experimental observations made by Sokratov (2001). He noted that the relative importance of temperature gradient was large when the temperature was high, and was negligible for low temperatures.

It appears that temperature-gradient metamorphism can be defined within the framework of minimum entropy production: applied temperature gradients induce slight differences between the ice and air because of the highly irregular and non-uniform granular structure of snow. Depending on the temperature and temperature difference, flat surfaces are required to minimize entropy production.

An observed feature of temperature-gradient metamorphism is that recrystallization rates stop at a limiting density (Sokratov, 2001). Bozhinskiy and Losev (1998) state that the limiting density is $350 \mathrm{~kg} \mathrm{~m}^{-3}$; Marbouty (1980) states a value of $400 \mathrm{~kg} \mathrm{~m}^{-3}$. A possible explanation for this phenomenon is that at higher densities, large grains prevail with bond sizes about the size of the grain radius (large $\alpha$ angles). In such a situation, the temperature difference between the ice and air vanishes since the cross-sectional areas of the ice and air are constant. Without irregularities, the temperature gradient cannot induce temperature differences across the interface and, subsequently, temperaturegradient metamorphism stops.

\subsection{Comparison of minimum entropy production with isothermal and temperature-gradient metamorphism}

A direct comparison can be made between minimum entropy production and mass diffusion theory. The results are presented in Table 4. Diffusion theory divides snow metamorphism into two regimes: isothermal- and temperaturegradient metamorphism. We take McClung and Schaerer (1993) as the standard reference describing these two regimes. We do not consider new snow metamorphism or wet snow metamorphism, for these would require different microstructural or thermodynamic models.

Table 4 shows the position of minimum entropy production within the framework of established metamorphism theory. It shows that the principle of minimum entropy production is not in contradiction with observations. Equilibrium conditions are likely to exist when the temperature gradients are small and the grains are tightly packed; nonequilibrium conditions are likely to exist under high temperature gradients and when the pore space is large. Isothermal metamorphism thus corresponds to minimum entropy production at equilibrium temperatures, and temperature-gradient metamorphism corresponds to minimum entropy production at non-equilibrium temperatures.

Table 4. The principle of minimum entropy production predicts form changes as a function of $\Delta T$. The widely accepted theory, from McClung and Schaerer (1993), is based on mass diffusion arising from temperature gradients. The two theories are not in contradiction

\begin{tabular}{|c|c|c|}
\hline Isothermal & Equilibrium temperatures & Small $\mathrm{d} T / \mathrm{d} z$ \\
\hline (1) Low growth rates & $\Delta T \approx 0$ & Tightly packed \\
\hline (2) Rounded grains & Smaller $r_{\mathrm{opt}}$ at colder temperatures & More rounded grains at colder temperatures \\
\hline Temperature gradient (TG) & $0^{\circ} \mathrm{C}<\Delta T<2 \mathrm{~K}$ & Large $\mathrm{d} T / \mathrm{d} z$ \\
\hline (1) Large growth rates & & Large pore space \\
\hline (2) Flat surfaces & Smaller $\Delta T$ needed at warmer temperatures & Higher growth rates at warmer temperatures \\
\hline
\end{tabular}




\section{SUMMARY AND CONGLUSIONS}

In summary, the theory of minimum entropy production predicts:

The dominant entropy production contribution arises from mass transfer across the interfacial boundary.

Entropy production minima are associated with flat, non-rounded grains.

Entropy production decreases with increasing temperature. At $T=T_{\mathrm{a}}=T_{\mathrm{i}}=273.15 \mathrm{~K}$ and flat surfaces $1 / r_{\mathrm{g}}=0$, entropy production appears to stop.

In isothermal conditions, $T=T_{\mathrm{a}}=T_{\mathrm{i}}$, the lower the absolute temperature, the smaller the curvature radius, depending directly on $\Delta p=p_{\mathrm{s}}\left(T_{\mathrm{i}}\right)-p_{\mathrm{v}}\left(T_{\mathrm{a}}\right)$.

The size of the bonds relative to the grain-size has an influence on the entropy production in both isothermaland temperature-gradient metamorphism. Hence, the ratio of bond size to grain-size could be an important parameter in snow metamorphism.

The optimal surface curvature in isothermal conditions is not the largest possible. Even flatter surfaces are possible in non-equilibrium conditions $\Delta T=T_{\mathrm{i}}-T_{\mathrm{a}} \neq 0$.

In order to obtain very flat grains (the maximum optimal radii) at lower temperatures, large temperature differences between the ice and air must be maintained.

Temperature-gradient metamorphism is defined within the framework of minimum entropy production as follows: Applied temperature gradients induce slight temperature differences between the ice and air because of the highly irregular and non-uniform granular structure of snow. Depending on the temperature and temperature difference, very flat surfaces are required to minimize entropy production.

Because the controlling physical process of snow metamorphism appears to be interfacial mass transport which is driven by temperature and concentration differences between the ice and air phases, physical snowpack models should be based on a non-equilibrium treatment of heat and mass transfer (Bartelt and others, 2004).

These results are based on an elementary application of the principle of minimum entropy production. We were unable to derive a more complicated production function in which the control volume contained more than one grain and bond. Only the volumetric constraint condition between the ice and pore air was used in this work. In order to determine grain-size (not only grain curvature), additional (and non-trivial) mass constraints will probably have to be invoked with larger control volumes. The formulation was also based on a rigid, non-deforming ice matrix. Entropy principles including irreversible mechanical deformations (Coleman and Noll, 1963) can and should be applied in future.

Finally, there is a fundamental assumption behind the invocation of the minimum entropy principle. We assume that non-equilibrium states can be deduced from principles of thermodynamic equilibrium (Jaynes, 1980). The practical consequence of this assumption is that it is impossible to say how a system behaves as a function of time. Therefore, it is impossible to state how fast the system attains the state of minimum entropy production. In principle, we cannot even say whether the system reaches this state or not. In our particular case, it is impossible for us to state how fast the grain curvature is changing; we can only suggest the general tendency or direction of the change. This is useful, but it is no substitute for rate equations. We must postulate: if a thermodynamic system can reduce entropy production by changing some variable(s), it will develop towards the minimum entropy production within the given constraints (Glansdorff and Prigogine, 1974). To find the implicit time dependence of entropy production on form will be the next challenge.

According to our analysis, the snow cover is in the neighborhood of equilibrium (Prigogine, 1980) because the entropy production principle appears to hold. This will allow us to apply linear non-equilibrium thermodynamics to the snow cover in the future.

\section{ACKNOWLEDGEMENTS}

This paper was originally submitted to Annals of Glaciology as part of the IGS 2003 Davos symposium on snow and avalanches. We thank our editor, M. Sturm, for his many helpful suggestions, which greatly improved the original paper, as well as his idea that we publish it in the fournal. We wish to thank the Swiss National Science Foundation for financial support for this work. Finally, we wish to thank an unknown 'entropy expert' as well as an unknown snow scientist for taking the time to review the paper and for their positive comments.

\section{REFERENGES}

Bartelt, P. and M. Lehning. 2002. A physical SNOWPACK model for the Swiss avalanche warning. Part I. Numerical model. Cold Reg. Sci. Technol., 35(3), 123-145.

Bartelt, P., O. Buser and S. Sokratov. 2004. A nonequilibrium treatment of heat and mass transfer in alpine snowcovers. Cold Reg. Sci. Technol., 39(2-3), 219-242.

Bejan, A. 1996. Entropy generation mimimization. Boca Raton, FL, CRC Press.

Bejan, A. 1997. Advanced engineering thermodynamics. Second edition. New York, John Wiley and Sons.

Bejan, A. 2000. Shape and structure, from engineering to nature. Cambridge, Cambridge University Press.

Bozhinskiy, A. N. and K. S. Losev. 1998. The fundamentals of avalanche science. Eidg. Inst. Schnee- und Lawinenforsch. Mitt. 55. (Translated from Russian by C. E. Bartelt.)

Brun, E., P. David, M. Sudul and G. Brunot. 1992. A numerical model to simulate snow-cover stratigraphy for operational avalanche forecasting. 7. Glaciol., 38(128), 13-22.

Buser, O. and W. Good. 1987. Acoustic, geometric and mechanical parameters of snow. International Association of Hydrological Sciences Publication 162 (Symposium at Davos 1986 - Avalanche Formation, Movement and Effects), 61-71.

Colbeck, S. C. 1983. Theory of metamorphism of dry snow. 7. Geophys. Res., 88(C9), 5475-5482.

Colbeck, S. C. 1987. A review of the metamorphism and classification of seasonal snow cover crystals. International Association of Hydrological Sciences Publication 162 (Symposium at Davos 1986 - Avalanche Formation, Movement and Effects), 3-34.

Coleman, B. D. and W. Noll. 1963. The thermodynamics of elastic materials with heat conduction and viscosity. Arch. Rat. Mech. Anal. 13(3), 167-178.

Glansdorf, P. and I. Prigogine. 1974. Thermodynamics theory of structure, stability and fluctuations. London, Wiley-Interscience.

Gubler, H. 1985. Model for dry snow metamorphism by interparticle vapor flux. 7. Geophys. Res., 90 (D5), 8081-8092.

Incropera, F. P. and D. P. DeWitt. 2002. Fundamentals of heat and mass transfer. Fourth edition. New York, etc., John Wiley and Sons.

Jaynes, E. 1980. The minimum entropy production principle. Ann. Rev. Phys. Chem., 31, 579-601.

Kaviany, M. 1995. Principles of heat transfer in porous media. Second edition. New York, etc., Springer-Verlag. 
Lehning, M., P. Bartelt, B. Brown, C. Fierz and P. Satyawali. 2002. A physical SNOWPACK model for the Swiss avalanche warning. Part II. Snow microstructure. Cold Reg. Sci. Technol., 35(3), 147-167.

Marbouty, D. 1980. An experimental study of temperature-gradient metamorphism. 7. Glaciol., 26(94), 303-312.

McClung, D. M. and P. A. Schaerer. 1993. The avalanche handbook. Seattle, WA, The Mountaineers.

Miller, D. 2002. An integrated microstructural study of dry snow metamorphism under generalized thermal conditions. (Ph.D. thesis, Montana State University.)

Prigogine, I. 1980. From being to becoming. San Francisco, W. H. Freeman and Company.

Shimizu, H. 1970. Air permeability of deposited snow. Contrib. Inst. Low Temp. Sci., Ser. A, 22, 1-32.

Sokratov, S. 2001. Parameters influencing the recrystallization rate of snow. Cold Reg. Sci. Technol., 33(2-3), 263-274.

MS received 7 August 2003 and accepted in revised form 24 February 2004 